\title{
Identification of Berberis Species Collected from the Himalayan Region of Pakistan Susceptible to Puccinia striiformis f. sp. tritici
}

\author{
Sajid Mehmood, ${ }^{1}$ Marina Sajid, ${ }^{2}$ Jie Zhao, ${ }^{1}$ Tika Khan, ${ }^{3}$ Gangming Zhan, ${ }^{1}$ Lili Huang, ${ }^{1,}$ and Zhensheng Kang ${ }^{1, \dagger}$ \\ ${ }^{1}$ State Key Laboratory of Crop Stress Biology for Arid Areas, College of Plant Protection, Northwest A\&F University, Yangling \\ 712100, Shaanxi, China; ${ }^{2}$ College of Food Science and Engineering, Northwest A\&F University, Yangling 712100, Shaanxi, \\ China; and ${ }^{3}$ Integrated Mountain Area Research Center, Department of Biological Sciences, Karakoram International \\ University, Gilgit 15100, Gilgit-Baltistan, Pakistan
}

\begin{abstract}
Puccinia striiformis f. sp. tritici (Pst), the stripe rust pathogen infecting cereal crops and grasses, was believed to have a hemicyclic life cycle consisting of uredinial and telial stages before the recent discovery of barberry (Berberis spp.) as an alternate (aecial) host for the fungus. This discovery has improved the understanding of the biology of the stripe rust pathogen. The Himalayan and near-Himalayan regions of Pakistan, China, and Nepal are considered as the center of diversity for Pst pathogen. High genetic diversity has been reported in these areas, probably resulting from the sexual reproduction of the stripe rust fungus. To

determine if Berberis species growing in Pakistan are susceptible to $P s t$, we collected seeds of five species and two subspecies from the Himalayan region in 2016 and inoculated the seedlings with germinated teliospores of a Pakistani Pst isolate under controlled conditions. Pycnia and aecia were produced on all inoculated plants of these species and subspecies, and were demonstrated as Pst by successful infection of wheat plants with aeciospores. This study showed that the tested Pakistani Berberis species and subspecies are susceptible to Pst under controlled conditions.
\end{abstract}

The life cycle of wheat stripe rust fungus Puccinia striiformis $\mathrm{f}$. sp. tritici (Pst) was previously thought to be hemicyclic consisting only of the uredinial and telial stages. The studies on genetic diversity of Pst in Europe, Australia, and North America have indicated a clonal population structure of the pathogen without sexual recombination (Hovmøller et al. 2002). In contrast, the Pst populations of Gansu Province, China, have been found to have high genetic diversity and produce abundant telia, indicating possible sexual recombination in this area (Duan et al. 2010; Mboup et al. 2009). In 2010, barberry (Berberis spp.) was discovered as an alternate host for $P$. pseudostriiformis (syn. P. striiformis f. sp. poae) (Liu and Hambleton 2010), under natural conditions in Minnesota (U.S.A.) and Pst under controlled conditions (Jin et al. 2010). Since then, the role of barberry as an alternate host of $P$ st has received a lot of attention, particularly in the United States, China, and Pakistan (Ali et al. 2014c; Mboup et al. 2009; Wang and Chen 2013, 2015; Wang et al. 2015; Zhao et al. 2013, 2016b). Under experimental conditions, Mahonia aquifolium has also been identified to be susceptible to Pst (Wang and Chen 2013). In China, 28 barberry spp. have been identified to be susceptible to $P$ st under controlled conditions, but so far natural Pst infections of barberry plants have been detected at very low frequencies and only on five Berberis spp. just in China (Wang et al. 2016; Zhao et al. 2013, 2016b). The role of Berberis spp. as susceptible hosts for Pst in other areas is unclear (Hovmøller et al. 2011; Jin et al. 2010; Wellings 2011).

Like other heteroecious and macrocyclic rust fungi, the life cycle of Pst consists of five spore stages: pycniospore (n), aeciospore

${ }^{\dagger}$ Corresponding authors: Lili Huang; E-mail: huanglili@ nwsuaf.edu.cn and Zhensheng Kang; E-mail: kangzs@nwsuaf.edu.cn

Funding: This work was supported by the National Key R \& D Program of China (2018YFD0200500), the 111 Project of the Ministry of Education of China (B07049), and the Natural Science Basic Research Plan in Shaanxi Province of China (2017JM3006).

*The $\boldsymbol{e}$-Xtra logo stands for "electronic extra" and indicates that two supplementary figures and two supplementary tables are published online.

Accepted for publication 1 September 2018.

(c) 2019 The American Phytopathological Society
$($ dikaryotic, $n+n)$, urediniospore (dikaryotic, $n+n)$, teliospore (diploid, $2 \mathrm{n}$ ), and basidiospore (haploid, $\mathrm{n}$ ). Uredinial, telial, and basidial stages occur on wheat and other related grasses serving as the primary host, and pycnial and aecial stages arise on its alternate hosts, Berberis spp. and Mahonia spp. Aeciospores and urediniospores both can infect wheat to produce new urediniospores. Basidiospores can infect the young leaves of Berberis spp. to produce pycniospores, which fertilize receptive hyphae to produce aeciospores.

Barberry plants have dimorphic shoots of attractive red or pink colors in autumn. Leaves are petiole, oblong, obovate, or ellipticacute with spinulose margins, usually white beneath. The flowers are produced singly or in racemes of up to 20 on a single flower head. Flowers are yellow or orange and are hermaphrodite. The berries are initially green, turn to yellow or pink, and eventually become red, blue, or black when they ripen. More detailed descriptions of Berberis spp. are given in Supplementary Table S1.

The genera Berberis and Mahonia have a large number of species and an extensive distribution around the world except for Australia. About 500 species of Berberis and 100 species of Mahonia have been recorded to date (Wan et al. 2017). Asia has the highest number of Berberis spp. among the seven continents. The best-known Berberis sp. is Berberis vulgaris (also known as European barberry or common barberry), which widely grows in central Asia, Europe, North Africa, and the Middle East and was introduced to North America from Europe. Approximately a half of the total numbers of Berberis spp. and Mahonia are native to China (Wan et al. 2017).

So far, 33 species of Berberis and one species of Mahonia (M. aquifolium) have been reported to be susceptible but only two Berberis spp. (B. coryi and B. vernalis) to be resistant to Pst based on tests under controlled conditions (Jin et al. 2010; Wang and Chen 2013; Zhao et al. 2013, 2016b). Under natural conditions, Pst infection of Berberis spp. has been detected only in China. In the Pacific Northwest of the United States, aecia on barberry plants were identified as Puccinia graminis, the causal agent of stem rust on wheat, barley, and grasses, but no $P$. striiformis (Wang et al. 2015). Wang and Chen (2015) identified several factors that prevent Pst from infecting barberry, including the structure of $P$. striiformis telia and teliospores, the lack of dormancy of teliospores, climatic conditions, and the phenology of barberry plants. Similarly, Pst has not been found on Berberis spp. in southeastern Sweden, but $P$. graminis is common on the alternate host plants in the region (Berlin et al. 2013). 
According to Khan et al. (2015a), 29 barberry species have been reported from Pakistan, of which 14, including two subspecies (B. pseudumbellata subsp. gilgitica and B. pseudumbellata subsp. pseudumbellata), were in the Gilgit-Baltistan Province. The estimated area in Gilgit-Baltistan with barberry plants is about $3,743 \mathrm{~km}^{2}$ (Khan et al. 2014a). The Himalayan regions in Pakistan, China, and Nepal have been suggested as a center of origin for Pst, for which sexual reproduction may play a role in virulence variation (Ali et al. 2014c). However, there were no studies on the susceptibility of Berberis spp. to Pst in Pakistan. Therefore, the objective of this study was to determine if the Berberis species commonly growing in the Himalayan region of Pakistan are susceptible to Pst under controlled greenhouse conditions.

\section{Materials and Methods}

Collection of seeds of Berberis spp. Surveys were conducted in Gilgit-Baltistan Province in the Himalayan region of Pakistan near the China-Pakistan border to collect seeds of different Berberis spp. in August and September 2016. The locations, altitudes, longitudes, and elevations of Berberis spp. were recorded during the surveys (Table 1). Seeds of five species and two subspecies were collected based on their morphological characteristics (Fig. 1; Supplementary Fig. S2) with the assistance of technical staff from the Department of Biological Sciences, Karakoram International University, Gilgit-Baltistan, Pakistan. The primary objective of these surveys was to collect seeds from as many Berberis spp. as possible. Seeds of five species and two subspecies, B. lycium (Adhikari et al. 2012), B. orthobotrys (Perveen and Qaiser 2010), B. pseudumbellata (Khan

Table 1. Survey locations of Berberis species and subspecies in the Himalayan region of Pakistan (Gilgit-Baltistan Province)

\begin{tabular}{|c|c|c|c|c|}
\hline No. & Berberis & Location & Latitude and longitude & Elevation (m) \\
\hline 1 & B. pseudumbellata subsp. pseudumbellata & Ghulmet, Rakaposhi Valley & N $36^{\circ} 14^{\prime} 22.96^{\prime \prime}$, E $74^{\circ} 29^{\prime} 03.89^{\prime \prime}$ & 1,989 \\
\hline 2 & B. pseudumbellata subsp. gilgitica & Chirah Village, Bugrote Valley, Tehsil Danyore & N $36^{\circ} 02^{\prime} 00.67^{\prime \prime}$, E $74^{\circ} 34^{\prime} 00.51^{\prime \prime}$ & 2,573 \\
\hline 3 & B. lycium & Rahimabad Goro, Nomal Valley & N $36^{\circ} 05^{\prime} 28.37^{\prime \prime}$, E $74^{\circ} 16^{\prime} 55.78^{\prime \prime}$ & 1,639 \\
\hline 4 & B. orthobotrys & Astore Valley & $\mathrm{N} 35^{\circ} 02^{\prime} 20.30^{\prime \prime}$, E $75^{\circ} 06^{\prime} 36.90^{\prime \prime}$ & 2,078 \\
\hline 5 & B. stewartiana & Gilgit Road 2800 m, Naltar Valley & N $36^{\circ} 09^{\prime} 22.67^{\prime \prime}$, E $74^{\circ} 11^{\prime} 57.19^{\prime \prime}$ & 2,723 \\
\hline 6 & B. brandisiana & Haramosh, Bugrote Valley & N $36^{\circ} 10^{\prime} 23.71^{\prime \prime}$, E $74^{\circ} 09^{\prime} 58.29^{\prime \prime}$ & 2,941 \\
\hline 7 & B. pseudumbellata & Hupay-Bugrote Valley & $\mathrm{N} 36^{\circ} 14^{\prime} 10.06^{\prime \prime}$, E $74^{\circ} 26^{\prime} 32.29^{\prime \prime}$ & 2,042 \\
\hline
\end{tabular}

A
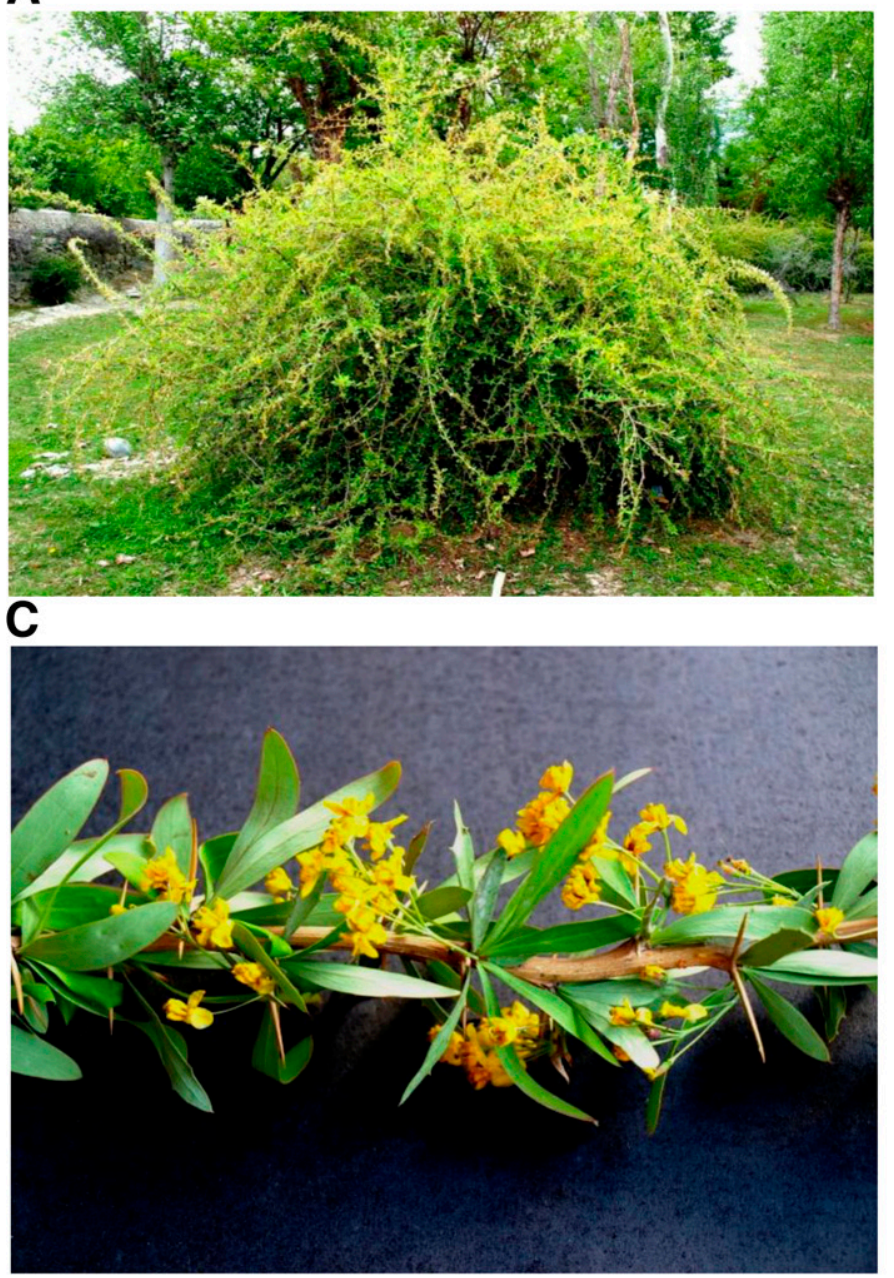

B

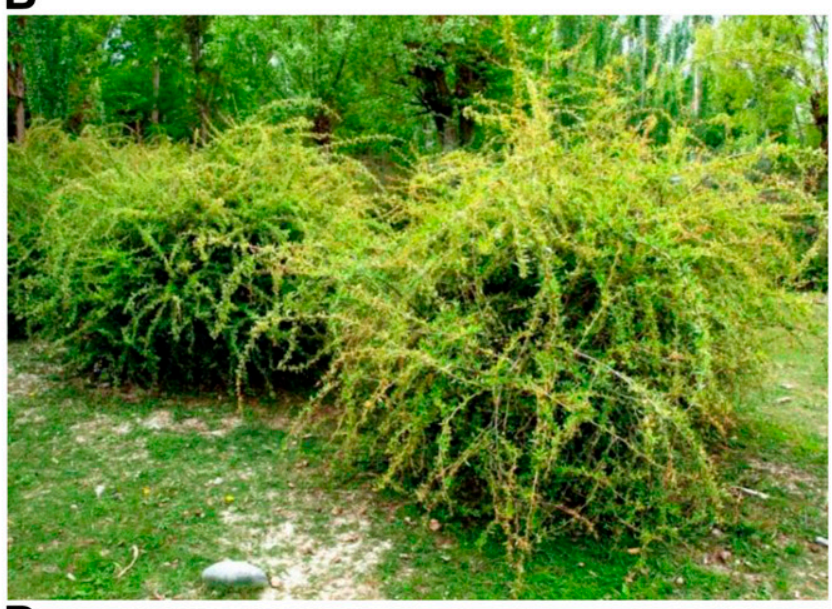

D

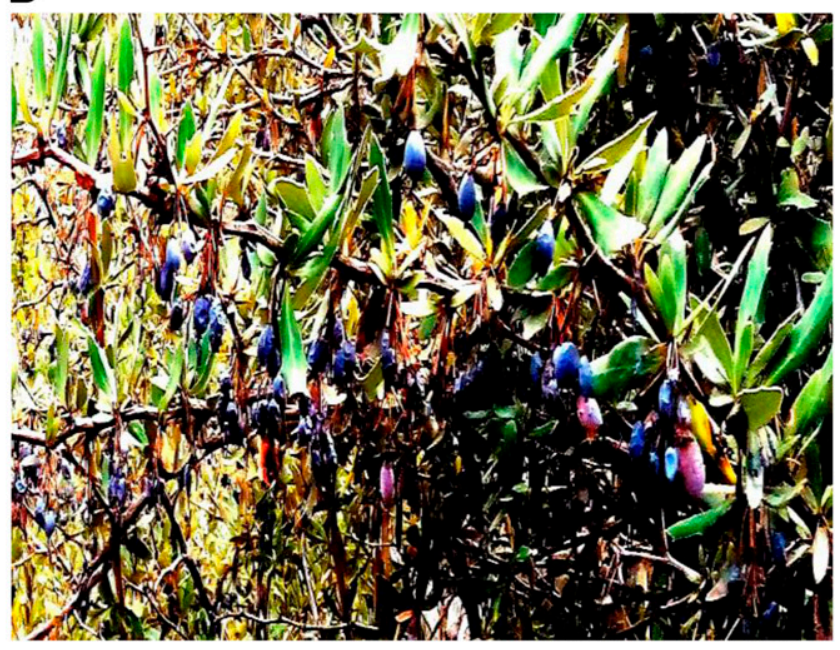

Fig. 1. A representative shrub of barberry species (Berberis pseudumbellata). A and B, growing naturally in the Himalayan region of Pakistan; C, inflorescence; and D, shoots with ripened berries. 
et al. 2014a), B. stewartiana (Khan et al. 2015b), B. brandisiana (Khan and Khatoon 2007), B. pseudumbellata subsp. pseudumbellata (Khan et al. 2014a), and B. pseudumbellata subsp. gilgitica (Khan et al. 2014a), were collected from different locations (Supplementary Fig. S1). Morphological characteristics of the five species and two subspecies are given in Supplementary Table S2. About 200 to 300 seeds of each species or subspecies were collected and kept in dry paper bags. The seeds were brought into the laboratory at Northwest A\&F University, Yangling, China, for further experiments.

Growing conditions for barberry plants. Barberry seeds of each species were mashed with a rubber mallet to break up the flesh and soaked in water overnight. After being rinsed thoroughly, the seeds were spread on a sheet of paper for $1 \mathrm{~h}$ to dry. Plastic pots of $7 \times$ $7 \times 7 \mathrm{~cm}$ were filled with a mixture of half medium-grit sand and half peat moss. The mixture was moistened, and two seeds were sown in each pot at a depth of $1.2 \mathrm{~cm}$. Each pot was watered to $2.4 \mathrm{~cm}$ depth and wrapped in a sheet of plastic wrap. Two or three small holes were poked through the plastic wrap. The pots were placed in a growth chamber at $10^{\circ} \mathrm{C}$ for 1 to 2 months to cold-stratify the seeds by maintaining moisture beneath the surface. Seeds germinated in 30 to 40 days, and one of the two seedlings, usually the smaller, was removed from each pot if both seeds had germinated successfully. At leaf stage three to four, the barberry seedlings were transplanted into bigger plastic pots $(10 \times 9 \times 7 \mathrm{~cm})$ filled with potting soil mixture (two parts compost, two parts peat moss), with one plant per pot and were kept in a growth chamber at 20 to $22^{\circ} \mathrm{C}, 16 / 8$-h light/ dark cycle, and 60 to $75 \%$ relative humidity (RH). The young plants were watered as needed for good growth.

Isolation of Pst. Wheat leaf samples bearing Pst uredinia were collected from an experimental field at the Barani Agriculture Research Institute, Punjab, Pakistan (32 ${ }^{\circ} 55^{\prime} 49^{\prime \prime} \mathrm{N}, 72^{\circ} 51^{\prime} 20^{\prime \prime} \mathrm{E}$, elevation $498 \mathrm{~m}$ ) in March to April 2016. The samples were identified as a dominant race, 574232 (Fayyaz et al. 2017). One of the leaf samples, [Pak-1-(A)-9], was brought to the lab at Northwest A\&F University, Yangling, China. The leaves were cut into pieces and placed onto moist filter papers in Pyrex Petri dishes (20 cm diameter). The dishes were taped using Parafilm to keep the moisture and placed in an incubator at $10^{\circ} \mathrm{C}$ for $10 \mathrm{~h}$ to produce fresh urediniospores. Tenday-old seedlings of the susceptible wheat cultivar Mingxian 169 were inoculated with urediniospores from a single uredinium by using a sterilized needle (Zhan et al. 2016). Inoculated seedlings were incubated in a dew chamber at 90 to $99 \% \mathrm{RH}$ for $24 \mathrm{~h}$ at $10^{\circ} \mathrm{C}$, and then the plants were moved to a growth room at $16^{\circ} \mathrm{C}$ with $16 / 8$-h light/dark cycle (Tian et al. 2016). After 15 days, urediniospores appeared on the surface of young leaves (Zhan et al. 2016). Urediniospores were collected in glass tubes and kept at $4{ }^{\circ} \mathrm{C}$ for further use.

Teliospore production. The isolate was used to produce teliospores. Plants of Mingxian 169 were raised in a spore-proof growth chamber at $18^{\circ} \mathrm{C}$ with a photoperiod of $16 / 8$-h light/dark cycle and a supplement of artificial light, 150 to $200 \mu \mathrm{mol} /\left(\mathrm{s} \cdot \mathrm{m}^{2}\right)$, and 70 to $80 \%$ RH. Adult plants at the growth stage 50 were inoculated (Zadoks et al. 1974). The inoculated plants were kept at $10^{\circ} \mathrm{C}$ for $24 \mathrm{~h}$ in a dew chamber at 90 to $99 \% \mathrm{RH}$ and then transferred to a growth chamber at $16^{\circ} \mathrm{C}$ with $16 / 8$-h light/dark cycle as described above. When uredinial sporulation reached its maximum level, the plants were moved to another growth chamber at $25 / 16^{\circ} \mathrm{C}$ day/night to accelerate the formation of teliospores (Tian et al. 2016; Zheng et al. 2013). About 35 to 40 days after inoculation (dai), leaves bearing telia were collected. The leaves were kept at $20^{\circ} \mathrm{C}$ for 2 days and then stored at $4^{\circ} \mathrm{C}$ in dry paper bags for further use.

Inoculation of barberry plants with germinated teliospores. Wheat leaf segments bearing $P s t$ telia were soaked in distilled water in a Petri dish (25 cm diameter) and kept at room temperature for 2 days. After rinsing with distilled water, the leaf segments were placed on $2 \%$ water agar medium and incubated at $10^{\circ} \mathrm{C}$ in the dark (Jin et al. 2010; Zhao et al. 2013). Teliospore germination was monitored using a light microscope. When abundant basidiospores were observed (usually 1 to 2 days after plating), the water agar plates having basidiospores were inverted and placed on the top of a plastic cylinder surrounding barberry plants bearing young leaves (10 to 15 days old). The inoculated barberry plants were incubated at $100 \% \mathrm{RH}$ for 3 days at $10^{\circ} \mathrm{C}$ in the dark (Zhao et al. 2013). The inoculated plants were kept in a spore-proof growth chamber with 90 to $100 \% \mathrm{RH}$, diurnal cycle of $16 / 13^{\circ} \mathrm{C}$, and $12 / 12$-h light/dark cycle to promote pycnial formation. Plants were observed for symptoms and signs and misted with water every day until pycnia appeared (12 to 14 dai) on the upper surface of the leaves. Pycnial nectar was picked from one pycnium and delivered to another using a sterilized toothpick for fertilization. About 18 to 22 dai, when aecia appeared on the abaxial surface of leaves, the RH was lowered to 60 to $70 \%$ to stop the opening of aecial cups (Rodriguez-Algaba et al. 2017). Images were taken using a Nikon D7200 digital SLR camera equipped with a SIGMA macro lens AF 105 mm F2.8 EX DGOS HSM for Nikon (Nikon, Tokyo, Japan).

Inoculation of wheat seedlings with aeciospores. Aeciospores from each Berberis species or subspecies were treated as a single isolate, and all seven isolates from the five species and two subspecies were tested on wheat cultivar Mingxian 169. To produce an aecial inoculum, aecial cups (1 to $3 \mathrm{~mm}$ in length) on the infected barberry leaves of a single species or subspecies were cut with a sterile blade and placed in a drop of deionized water on a glass slide. The aecial cups were crushed gently with a needle to release aeciospores. The aeciospore suspension was used to inoculate first leaves of Mingxian 169 seedlings grown for 10 days after planting with a sterile needle. The inoculated seedlings were incubated for $24 \mathrm{~h}$ in a dew chamber at $10^{\circ} \mathrm{C}$ and then transferred to a growth room at $16^{\circ} \mathrm{C}$ with a diurnal cycle of 16/8-h light/dark. The inoculated seedlings were isolated with plastic cylinders with open tops to prevent contamination (Zhao et al. 2013). The plants were checked for symptoms and signs about 12 days, and uredinial sporulation was recorded 15 to 20 days after aeciospore inoculation.

\section{Results}

Berberis species and subspecies in the Himalayan region of Pakistan. Surveys were conducted mainly in Gilgit-Baltistan Province in the Himalayan region of Pakistan bordering in the east and northeast with the Xinjiang region of China. Seeds from five barberry species and two subspecies were collected. The morphological characteristics of these species and subspecies are provided in the supplementary material. The species and subspecies were found in places of different altitudes and latitudes (Table 1). Abundant plants of B. pseudumbellata subsp. pseudumbellata were observed in different parts of Gilgit-Baltistan including Hunza, Nagar, Gilgit, Ghizer, Naltar, Bugrote, Rakaposhi, Haramosh, and Astore valleys. B. pseudumbellata subsp. gilgitica was abundant in the Bugrote valley. $B$. orthobotrys was largely distributed in the Astore valley. B. brandisiana was found in the Haramosh and Bugrote valleys. B. lycium was distributed enormously in northern Gilgit-Baltistan.

In the investigated areas, barberry plants primarily start regrowing in March. Flowering usually begins in April and reaches its peak in May to June. Fruiting occurs in the dry season, mostly in July to August. Seeds mature in the cold season, mainly in November to December, and germinate in the following spring. The majority of barberry species shed leaves in January to February, and new leaves start growing in March.

Susceptibility of Berberis species or subspecies to Pst. All tested Berberis species and subspecies, inoculated with germinated teliospores under controlled greenhouse conditions, produced orangecolored pycnia on the upper side of leaves 12 to 14 dai and orange to yellow aecia on the lower surface of the infected leaves 18 to 22 dai. Very heavy infection was found on plants of $B$. pseudumbellata (Fig. 2, A and a) and B. pseudumbellata subsp. pseudumbellata (Fig. $2, \mathrm{~B}$ and $\mathrm{b}$ ). The sizes of the aecial cups were 1 to $3 \mathrm{~mm}$ in length. Heavy infection was observed in B. orthobotrys (Fig. 2, C and c) and $B$. brandisiana (Fig. 2, D and d), with long aecial cups (3 to $5 \mathrm{~mm}$ in length). High infection was also observed on B. lycium (Fig. 2, E and e), producing massive aecia. Moderate pycnial and aecial formations were observed on B. pseudumbellata subsp. gilgitica (Fig. 2, F and f). Massive pycnia and aecia were observed on the 


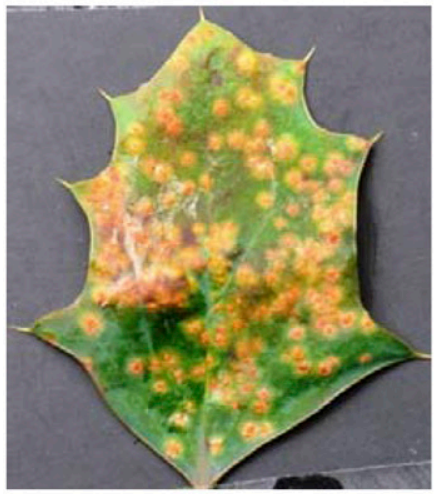

A

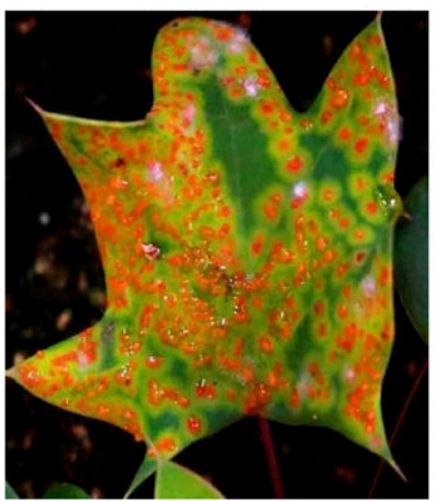

C

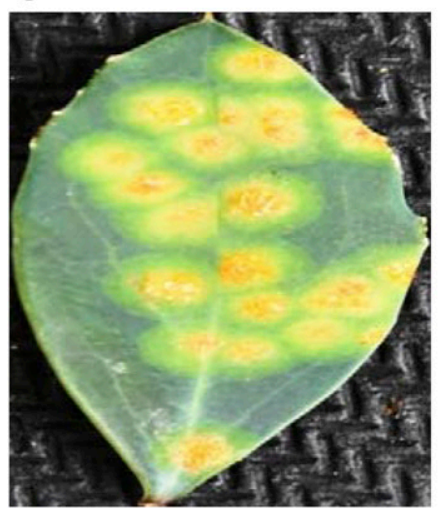

E

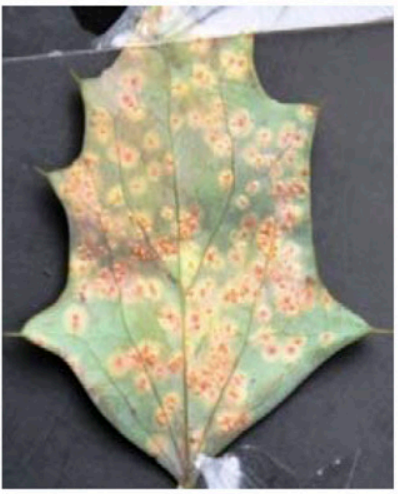

a

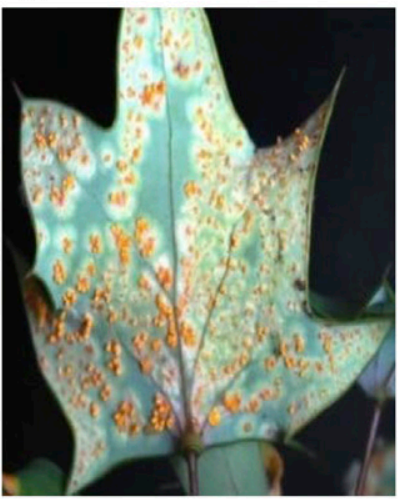

c

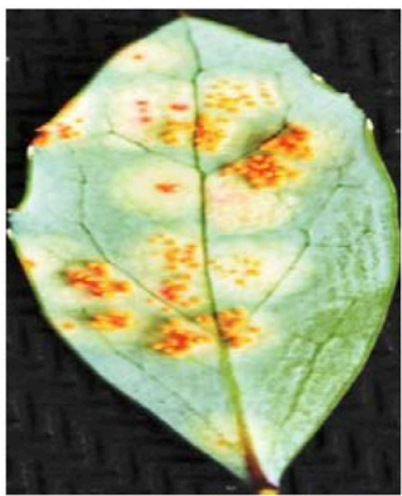

e

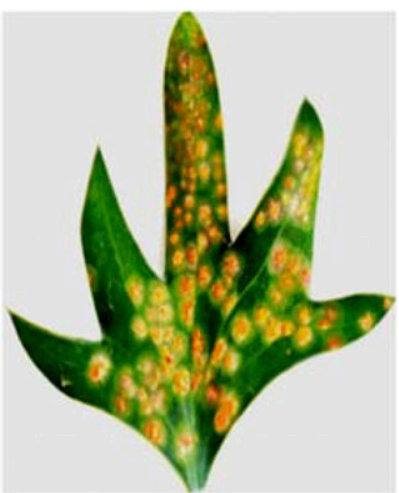

G

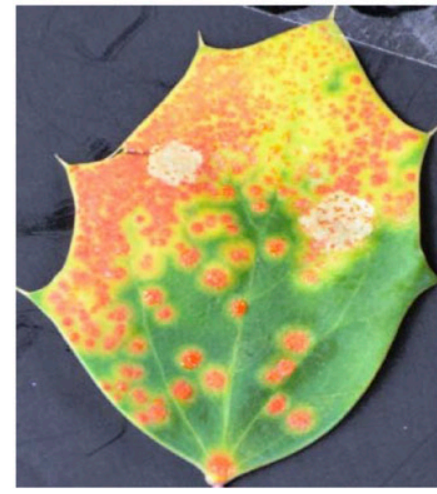

B

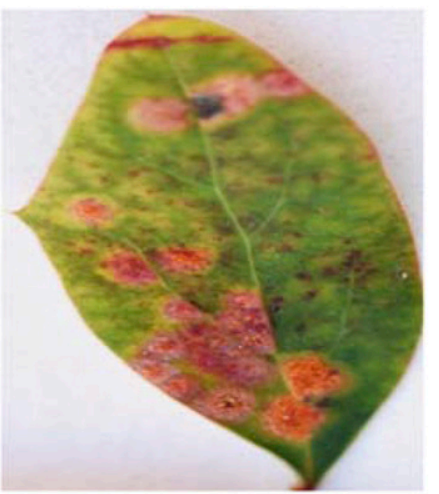

D

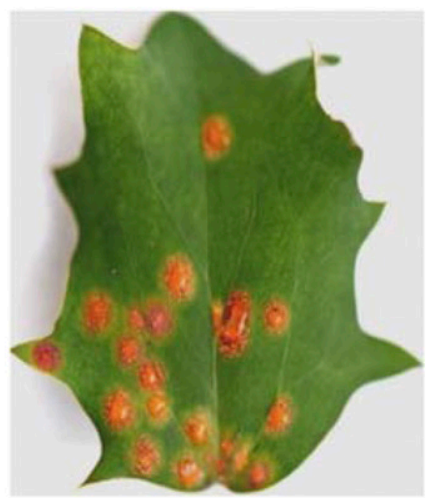

F

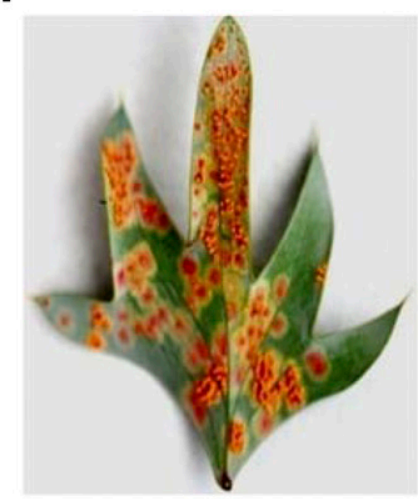

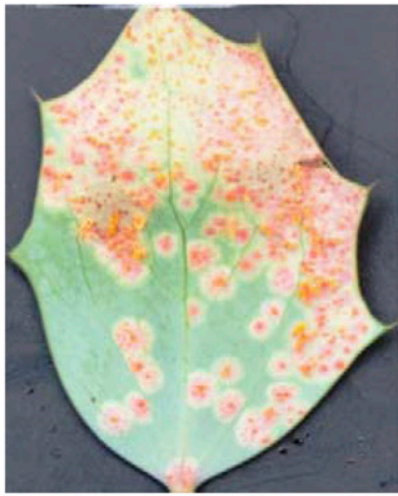

b

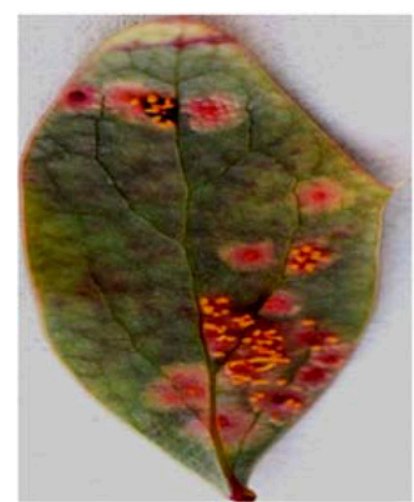

d

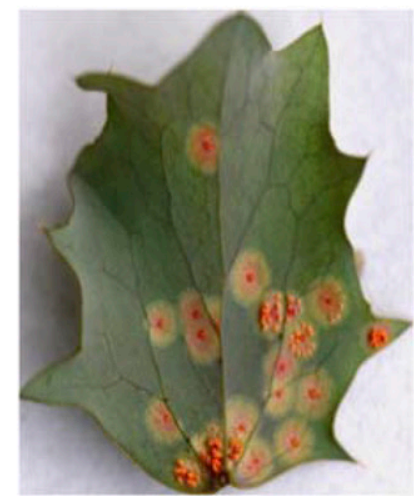

f

g

Fig. 2. Reactions of five Pakistani Berberis species and two subspecies to Pakistani isolate [Pak-1-(A)-9] of Puccinia striiformis f. sp. tritici, inoculated artificially under controlled greenhouse conditions. Images marked with capital letters show pycnia on the upper surface of leaves, and those marked with lowercase letters show aecia on the lower sides of leaves. A and $\mathbf{a}$, B. pseudumbellata; $\mathbf{B}$ and $\mathbf{b}$, B. pseudumbellata subsp. pseudumbellata; $\mathbf{C}$ and $\mathbf{c}, \mathbf{B}$. orthobotrys; $\mathbf{D}$ and $\mathbf{d}, B$. brandisiana; $\mathbf{E}$ and $\mathbf{e}, B$. lycium; F and $\mathbf{f}, B$. pseudumbellata subsp. gilgitica; and $\mathbf{G}$ and $\mathbf{g}, B$. stewartiana. 
leaves of B. stewartiana (Fig. 2, G and g). The mean size of the aecial cups of the tested species or subspecies ranged from 0.5 to $5 \mathrm{~mm}$ in length. Pycnia were also observed on stems and pedicels and aecia on peduncles of young leaves of barberry plants.

Seedlings of Mingxian 169 inoculated with aeciospores from all tested barberry species and subspecies produced Pst uredinia about 15 to 20 dai (Fig. 3). The results showed that these five Pakistani Berberis species and two subspecies were susceptible to Pst when artificially inoculated under controlled greenhouse conditions.

\section{Discussion}

The investigation of barberry plants as alternate hosts for Pst is essential to understanding the life cycle and evolution of the pathogen. Several previous studies identified more than 30 Berberis species susceptible to Pst under controlled conditions (Jin et al. 2010; Wang et al. 2016; Zhao et al. 2013, 2016a). Under natural conditions, five Berberis species have been reported to be infected by Pst in China (Wang et al. 2016; Zhao et al. 2013, 2016b). However, in some parts of the world, barberry was not found as an alternate host for Pst (Berlin et al. 2013; Wang and Chen 2015; Wang et al. 2016). Before the present study, there was no report on barberry susceptibility to $P s t$ in Pakistan. In the present study, we found wide spread growth of various Berberis species in the Himalayan region of Pakistan and identified seven species or subspecies commonly grown in the region all to be susceptible to Pst under controlled greenhouse conditions. The results increased the number of Pst-susceptible Berberis and Mahonia species/subspecies from the previously known 33 to 40 (Zhao et al. 2016a).

In the present study, the seeds of tested Berberis species/ subspecies were collected from Gilgit-Baltistan Province, Pakistan, which is part of the Himalayan region considered a center of diversity for $P s t$ and other cereal rust fungi (Ali et al. 2014a, b, c). A total of 29 Berberis species and subspecies have been reported to grow in various parts of Pakistan and 14 of them in Gilgit-Baltistan (eFlora 2014; Jafri 1975; Khan et al. 2014a, b). During our survey, barberry plants were found near wheat fields, on mountain slopes, close to streams, and at river banks. We observed that B. pseudumbellata subsp. pseudumbellata and B. pseudumbellata subsp. gilgitica were the most common species in the surveyed region, similar to the previous report (Khan et al. 2015a, b). In the present study, we collected seeds from five species and two subspecies based on their distinct morphological characteristics and abundant plants in the region. We did not include other species mainly because many of these species were not easy to distinguish (Khan et al. 2015b) and/or difficult to collect seeds. Further studies are needed to test other species.

Gilgit-Baltistan covers an area of $72,971 \mathrm{~km}^{2}$, and about $98 \%$ of the land is mountainous and only $2 \%$ is arable. Wheat is largely grown as a winter crop in valleys to fulfill the requirements for human food and animal feed. In the lower parts $(1,200$ to $1,900 \mathrm{~m}$ above sea level) of valleys, a double-cropping system is used for growing two staple crops, wheat in November to May and maize from June to October. In the areas of high altitudes (2,300 to 3,000 $\mathrm{m}$ above sea level), maize is the main crop grown from May to October or June to November, and summer-sown wheat is grown as a secondary or minor crop (Ali et al. 2014c; Hashmi and Shafiullah 2003). Thus, in our surveyed region, both primary and alternate hosts coexist, an ecological condition required for $P s t$ to complete the macrocyclic lifecycle on these distinct plants. Jin et al. (2010) have hypothesized that in areas where wheat and stripe rust-susceptible Berberis spp. coexist, sexual recombination likely plays an active role in contributing to the variability of Pst.

The phenology of barberry plants and environmental conditions are important for any rust pathogens to infect and develop on the primary and alternate hosts in a particular region. In the U.S. Pacific Northwest, Pst usually produces teliospores on winter wheat from June to July and on spring wheat from July to August (Wang and Chen 2015). Mature teliospores scratched from wheat plants can be easily germinated under controlled conditions. As time passes, the germination rate will decrease. Under moist conditions, Pst teliospores lose viability quickly. The majority of the annual precipitation in the region occurs during the wintertime (November to February). After wet winter, telia on wheat stubble in the field are degraded and teliospores lose viability. When new leaves start growing from midApril to early May, there are no viable teliospores. Thus, they did not detect any $P$ st aecia on barberry plants. In contrast, $P$. graminis f. sp. tritici ( $P g t$, the wheat and barley stem rust pathogen) produces telia for a much shorter time from June to July because the region usually has limited precipitation needed for $P g t$ infection during the summer. Because of the dormancy, Pgt teliospores cannot germinate until the winter is over and reach the highest germination level in April to May, perfectly catching susceptible young leaves of barberry plants to infect in May to June, producing and releasing aeciospores to infect cereal crops in June and July. Because Pgt usually cannot survive the winter in this region and urediniospores from outside of the region are usually too late to cause an epidemic, barberry plays an essential role for stem rust epidemic in this region (Wang and Chen 2015; Wang et al. 2015). In the Himalayan region of Pakistan, barberry plants produce new leaves in the spring season (March to mid-April). Pst produces telia usually in late May to late June in the winter wheat areas of low elevations and in the spring wheat areas of high elevations in October to November (Ali et al. 2014b). Wang and Chen (2015) pointed out that in the regions where the winter is dry and spring is wet, such as northwestern China, Pst teliospores can survive the winter and may be able to infect barberry. The Himalayan region of Pakistan has such climate conditions, and therefore Pst may be able to infect barberry.
A

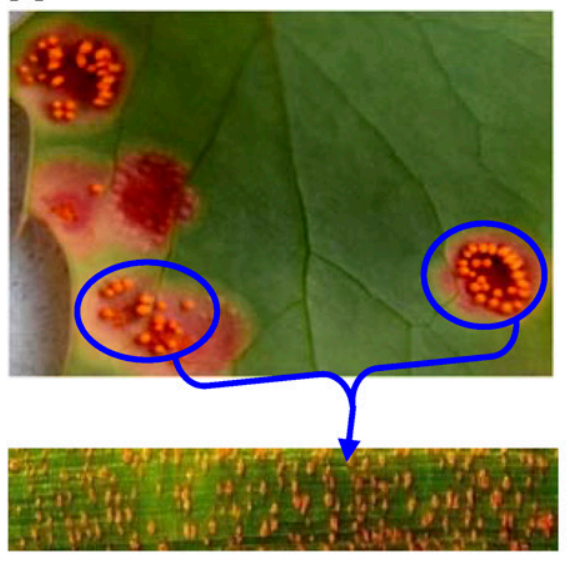

B

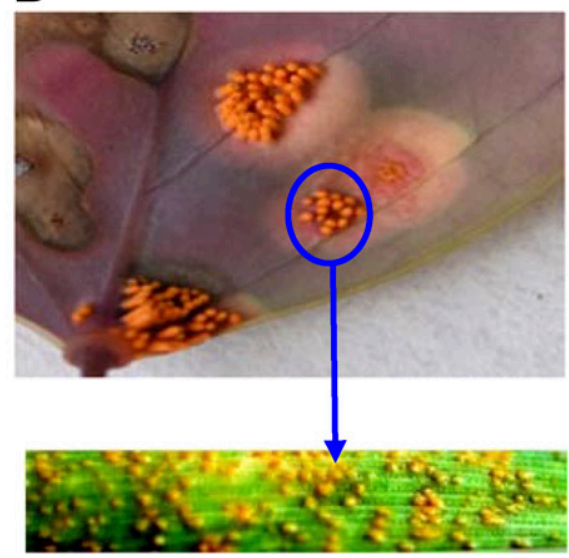

C

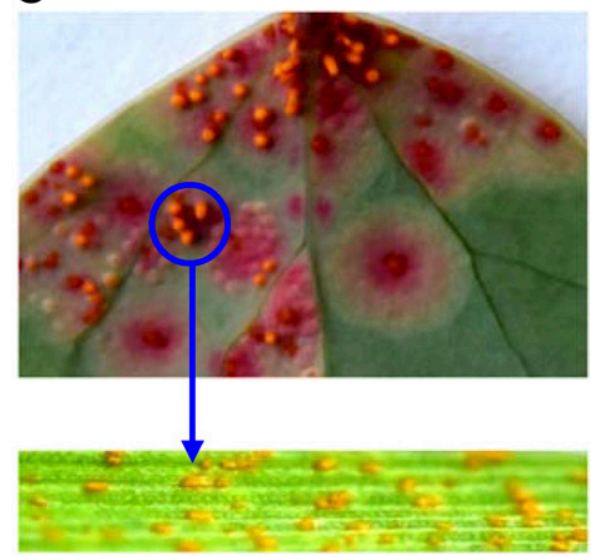

Fig. 3. Inoculation of wheat cultivar Mingxian 169 seedlings with aeciospores from leaves of five Pakistani Berberis species and two subspecies with Pakistani isolate [Pak-1-(A)-9] of Puccinia striiformis f. sp. tritici successfully produced uredinia under controlled greenhouse conditions. A, aeciospores from a leaf of $B$. pseudumbellata subsp. pseudumbellata; B, B. pseudumbellata subsp. gilgitica; and C, B. lycium. 
Ali et al. (2014b) studied the temporal maintenance of Pst populations from the normal wheat-growing seasons (winter) to off-season (summer) in the Himalayan region of Pakistan. They suggested a sink and source relationship between non-Berberis and Berberis zones for the importance of the sexual cycle of Pst populations in the region. Pst basidiospores could potentially infect barberry spp. in the Himalayan region if the teliospores on wheat plants are able to germinate in the spring or late in the fall and remain throughout the dry winter as reported in Gansu, China (Wang et al. 2016; Zhao et al. 2013). However, whether barberry plants provide aeciospores to start stripe rust in wheat crops in the Himalayan region needs further study. Identification of aecia on naturally infected barberry plants by infecting wheat plants and using molecular markers, as done by Wang et al. (2015), is the most direct and powerful approach to answer the questions whether and to what extent barberry is important for stripe rust in the Himalayan region of Pakistan and other regions in the world.

We did not observe significant differences in the latent period (days between inoculation and pycnial formation) among the tested five Berberis species and two subspecies (data not shown). However, we noticed the differences in the times of pycnial and aecial formations in the present study compared with the previous studies. In the present study, pycnia on the adaxial surface of leaves appeared 12 to 14 dai, and aecia appeared on the abaxial surface of leaves 18 to 22 dai, which was different from previous studies. For example, Jin et al. (2010) observed pycnia and aecia 8 and 14 dai, Zhao et al. (2013) 9 and 17 dai, and Wang and Chen (2013) 12 and 16 dai, respectively. The difference could be owing to the different temperatures and other conditions used in these tests, different Pst isolates, and different species of the alternate hosts.

In the present study, we observed that the color of pycnia was orange and aecia or aecial cups were orange to yellow. However, Wang and Chen (2013) observed reddish pycnia and aecia on inoculated leaves of M. aquifolium. Zhao et al. (2013) observed yellow to red color of the mature aecia on the abaxial surface of barberry leaves under natural conditions. Berlin et al. (2013) in Sweden observed two types of aecia on barberry plants naturally infected by $P$. graminis: yellow, light orange, cup-like localized aecia and bright yellow to brownish powder-like aecia covering the entire surface of leaves. These studies show that different Puccinia species may have color variation in their pycnial and aecial stages. Even for a single forma specialis of $P$. striiformis, such as $P$ st, the colors of pycnia and aecia could be different with different isolates and Berberis spp. The different colors could be caused by different $P$ st isolates, Berberis and $M a$ honia species, and test conditions.

The sizes of $P s t$ aecial cups also vary greatly. In the present study, we observed that the sizes of aecial cups on B. pseudumbellata and $B$. pseudumbellata subsp. pseudumbellata were small (1 to $3 \mathrm{~mm}$ in length), whereas on $B$. orthobotrys and $B$. brandisiana aecial cups were large (3 to $5 \mathrm{~mm}$ in length). On B. lycium, B. pseudumbellata subsp. gilgitica, and $B$. stewartiana, aecial cups ranged from 0.5 to $5 \mathrm{~mm}$ in length. The average number of aecial cups in one aecium was 10 to 20, depending upon different Berberis spp. These results were similar to the study of Wang et al. (2015), because they reported the aecial cup size ranging from 0.2 to $2.0 \mathrm{~mm}$ in length, and the number of aecial cups in one aecium was mostly 10 to 20 .

In addition to leaves, Pst can infect other parts of barberry plants. We observed pycnia on stems and leaf pedicels of the artificially inoculated young barberry plants. Rodriguez-Algaba et al. (2014) observed pycnia at both adaxial and abaxial surfaces of leaves, stems, and pedicels of B. vulgaris. Similarly, Wang et al. (2015) observed aecia on leaves, immature fruits, and the peduncles of young berries on naturally infected barberry plants, although these aecia were identified as $P$. graminis.

In the present study, we recorded different levels of susceptibility to Pst among the barberry species and subspecies based on relative abundance of pycnia and aecia in a qualitative manner, similar to the previous studies (Wang et al. 2016; Zhao et al. 2013). Although the number of basidiospores for inoculating each plant was not counted, the similar number of telia from the same number and same length of wheat leaf pieces bearing heavy telia in each Petri dish provided a similar amount of inoculum for each inoculated barberry plant. Because the inoculated young leaves of different Berberis species were slightly different and the sizes of pycnia and aecia were different, we just visually scored infections as "very heavy," "heavy," and "moderate," mainly based on the number of pustules in similar sizes of leaf areas. These data provide an indication of the relative levels of susceptibility of these species or subspecies. All of these species and subspecies were tested with a single $P s t$ isolate from wheat. Future tests of the different species and subspecies could be done in a more quantitative way with different Pst isolates to determine if there are any interactions between different isolates and Berberis spp.

As we determined the Berberis species and subspecies from the Himalayan region of Pakistan susceptible to Pst, barberry plants growing in this region may produce aecial inoculum to infect wheat crops and generate new pathotypes with different combinations of virulence genes through sexual reproduction if they can be infected under natural conditions. However, further studies are needed to obtain evidence directly from naturally infected barberry plants and study the rate of barberry infection and its role in wheat stripe rust epidemics in this region. The present study provides the distribution of barberry plants in the Himalayan region of Pakistan for further investigations of Pst on barberry plants. Based on the phenology of barberry plants in this region as discussed above, from March to the middle of April is the best time to collect aecial samples in the region.

\section{Literature Cited}

Adhikari, B., Pendry, C. A., Pennington, R. T., and Milne, R. I. 2012. A revision of Berberis S.S. (Berberidaceae) in Nepal. Edinb. J. Bot. 69:447-522.

Ali, S., Gladieux, P., Leconte, M., Gautier, A., Justesen, A. F., Hovmoller, M. S., Enjalbert, J., and de Vallavieille-Pope, C. 2014a. Origin, migration routes and worldwide population genetic structure of the wheat yellow rust pathogen Puccinia striiformis f. sp. tritici. PLoS Pathog 10:e1003903.

Ali, S., Gladieux, P., Rahman, H., Saqib, M. S., Fiaz, M., Ahmad, H., Leconte, M., Gautier, A., Justesen, A. F., Hovmøller, M. S., Enjalbert, J., and de VallavieillePope, C. 2014b. Inferring the contribution of sexual reproduction, migration and off-season survival to the temporal maintenance of microbial populations: A case study on the wheat fungal pathogen Puccinia striiformis f. sp. tritici. Mol. Ecol. 23:603-617.

Ali, S., Leconte, M., Rahman, H., Saqib, M. S., Gladieux, P., Enjalbert, J., and de Vallavieille- Pope, C. 2014c. High virulence and pathotype diversity of Puccinia striiformis f. sp. tritici at its centre of diversity, the Himalayan region of Pakistan. Eur. J. Plant Pathol. 140:275-290.

Berlin, A., Kyaschenko, J., Justesen, A. F., and Yuen, J. 2013. Rust fungi forming aecia on Berberis spp. in Sweden. Plant Dis. 97:1281-1287.

Duan, X., Tellier, A., Wan, A., Leconte, M., de Vallavielle-Pope, C., and Enjalbert, J. 2010. Puccinia striiformis f. sp tritici presents high diversity and recombination in the over-summering zone of Gansu, China. Mycologia 102: 44-53.

eFlora. 2014. Flora of Pakistan. eFloras.org. retrieved on May 11, 2017. http:// www.efloras.org/florataxon.aspx?flora_id=5\&taxon_id=242420754

Fayyaz, M., Shahzad, A., Ali, G. M., Rattu, A. R., and Muhammad, F. 2017. Identification of stripe rust (Puccinia striiformis) resistant genes among Pakistani spring wheat by using molecular markers. Int. J. Biosci. 11: 320-334.

Hashmi, A. A., and Shafiullah. 2003. Northern Areas Strategy for Sustainable Development Background Paper: Agriculture and Food Security. IUCN Pakistan, Northern Areas Programme, Planning and Development Department, Karachi, Pakistan. ISBN 969-8141-42-1.

Hovmøller, M. S., Justesen, A. F., and Brown, J. K. M. 2002. Clonality and longdistance migration of Puccinia striiformis $\mathrm{f}$. sp tritici in north-west Europe. Plant Pathol. 51:24-32.

Hovmøller, M. S., Sørensen, C. K., Walter, S., and Justesen, A. F. 2011. Diversity of Puccinia striiformis on cereals and grasses. Annu. Rev. Phytopathol. 49: 197-217.

Jafri, S. M. H. 1975. Berberidaceae. Pages 1-40 in: Flora of Pakistan No. 87. E. Nasir and S. I. Ali, eds. Department of Botany, University of Karachi, Pakistan.

Jin, Y., Szabo, L. J., and Carson, M. 2010. Century-old mystery of Puccinia striiformis life history solved with the identification of Berberis spp. as an alternate host. Phytopathology 100:432-435.

Khan, S. W., and Khatoon, S. 2007. Ethnobotanical studies on useful trees and shrubs of Haramosh and Bugrote valleys, in Gilgit northern areas of Pakistan. Pak. J. Bot. 39:699-710.

Khan, T., Khan, I. A., Ahmed, K., and Rehman, A. 2014a. A review on Berberis species reported from Gilgit-Baltistan and Central Karakoram National Park, Pakistan. J. Med. Plants Stud. 2:16-20. 
Khan, T., Khan, I. A., Ahmed, K., and Rehman, A. 2014b. Elaboration of phylogenetic studies in Berberis spp. from Karakorum Ranges. II. Floral and morpho-pathological data. Int. J. Biosci. 5:133-142.

Khan, T., Khan, I. A., and Rehman, A. 2015a. Evaluation and detailing of taxonomic and historical perspectives on genus Berberis from Pakistan. J. Biol. Environ. Sci. 6:361-367.

Khan, T., Khan, I. A., Rehman, A., and Karim, K. 2015b. Spatial distribution of genus Berberis from Pakistan: A review over three centuries long historical records. J. Biol. Environ. Sci. 6:341-352.

Liu, M., and Hambleton, S. 2010. Taxonomic study of stripe rust, Puccinia striiformis sensu lato, based on molecular and morphological evidence. Fungal Biol. 114:881-899.

Mboup, M., Leconte, M., Gautier, A., Wan, A. M., Chen, W., de VallavieillePope, C., and Enjalbert, J. 2009. Evidence of genetic recombination in wheat yellow rust populations of a Chinese oversummering area. Fungal Genet. Biol. 46:299-307.

Perveen, A., and Qaiser, M. 2010. Pollen flora of Pakistan-LXV. Berberidaceae. Pak. J. Bot. 42:1-6.

Rodriguez-Algaba, J., Sørensen, C. K., Labouriau, R., Justesen, A. F., and Hovmøller, M. S. 2017. Genetic diversity within and among aecia of the wheat rust fungus Puccinia striiformis on the alternate host Berberis vulgaris. Fungal Biol. 121:541-549.

Rodriguez-Algaba, J., Walter, S., Sørensen, C. K., Hovmøller, M. S., and Justesen, A. F. 2014. Sexual structures and recombination of the wheat rust fungus Puccinia striiformis on Berberis vulgaris. Fungal Genet. Biol. 70:77-85.

Tian, Y., Zhan, G. M., Chen, X., Tungruentragoon, A., Lu, X., Zhao, J., Huang, L. L., and Kang, Z. S. 2016. Virulence and simple sequence repeat marker segregation in a Puccinia striiformis f. sp. tritici population produced by selfing a Chinese isolate on Berberis shensiana. Phytopathology 106:185-191.

Wan, A., Wang, X., Kang, Z., and Chen, X. 2017. Variability of the stripe rust pathogen. Pages 35-154 in: Stripe Rust. X. Chen and Z. Kang, eds. Springer, Dordrecht, the Netherlands.

Wang, M. N., and Chen, X. M. 2013. First report of Oregon grape (Mahonia equifolium) as an alternate host for the wheat stripe rust pathogen (Puccinia striiformis f. sp. tritici) under artificial conditions. Plant Dis. 97: 839.
Wang, M. N., and Chen, X. M. 2015. Barberry does not function as an alternate host for Puccinia striiformis f. sp. tritici in the US Pacific Northwest due to teliospore degradation and barberry phenology. Plant Dis. 99:1500-1506.

Wang, M. N., Wan, A. M., and Chen, X. M. 2015. Barberry as alternate host is important for Puccinia graminis f. sp. tritici but not for Puccinia striiformis f. sp. tritici in the U.S. Pacific Northwest. Plant Dis. 99:1507-1516.

Wang, Z. Y., Zhao, J., Chen, X. M., Peng, Y. L., Ji, J. J., Zhao, S. L., Lv, Y. J., Huang, L. L., and Kang, Z. S. 2016. Virulence variations of Puccinia striiformis f. sp. tritici isolates collected from Berberis spp. in China. Plant Dis. 100:131-138.

Wellings, C. R. 2011. Global status of stripe rust: A review of historical and current threats. Euphytica 179:129-141.

Zadoks, J. C., Chang, T. T., and Konzak, C. F. 1974. A decimal code for the growth stages of cereals. Weed Res. 14:415-421.

Zhan, G. M., Wang, F. P., Chen, X. M., Wan, C. P., Han, Q. M., Huang, L. L., and Kang, Z. S. 2016. Virulence and molecular diversity of the Puccinia striiformis f. sp. tritici population in Xinjiang in relation to other regions of western China Plant Dis. 100:99-107.

Zhao, J., Wang, L., Wang, Z. Y., Chen, X. M., Zhang, H. C., Yao, J. N., Zhan, G. M., Chen, W., Huang, L. L., and Kang, Z. S. 2013. Identification of eighteen Berberis species as alternate hosts of Puccinia striiformis f. sp. tritici and virulence variation in the pathogen isolates from natural infection of barberry plants in China. Phytopathology 103:927-934.

Zhao, J., Wang, M., Chen, X. M., and Kang, Z. S. 2016a. Role of alternate hosts in epidemiology and pathogen variation of cereal rusts. Annu. Rev. Phytopathol. 54:207-228.

Zhao, J., Zhao, S. L., Peng, Y. L., Qin, J. F., Huang, L. L., and Kang, Z. S. 2016b. Investigation on geographic distribution and identification of six Berberis spp. serving as alternate host for $P$. striiformis f. sp. tritici in Linzhi, Tibet. Acta Phytopathol. Sin. 46:103-111.

Zheng, W. M., Huang, L. L., Huang, J. Q., Wang, X. J., Chen, X. M., Zhao, J., Guo, J., Zhuang, H., Qiu, C. Z., Liu, J., Liu, H. Q., Huang, X. L., Pei, G. L., Zhan, G. M., Tang, C. L., Cheng, Y. L., Liu, M. J., Zhang, J. S., Zhao, Z. T., Zhang, S. J., Han, Q. M., Han, D. J., Zhang, H. C., Zhao, J., Gao, X. N., Wang, J. F., Ni, P. X. Dong, W., Yang, L. F., Yang, H. M., Xu, J. R., Zhang, G. Y., and Kang, Z. S. 2013. High genome heterozygosity and endemic genetic recombination in the wheat stripe rust fungus. Nat. Commun. 4:2673. 